\title{
Structural Performance of Chemically Modified Natural Jute Yarn for Strength Demanding Composite Applications
}

\section{Ashadujjaman}

Dhaka University of Engineering \& Technology

\section{Abu Saifullah}

Advanced Materials and Manufacturing (AMM) Research Group, School of Mechanical and Design Engineering, University of Portsmouth, Portsmouth P01 3DJ, UK

\section{Darshil Shah}

Department of Architecture, University of Cambridge, Cambridge, CB2 1PX, UK

\section{Minglonghai Zhang}

Institute of Textile and Clothing, The Hong Kong Polytechnic University, Hong Kong

\section{Mahmudul Akonda}

School of Materials. The University of Manchester, Manchester, M13 9PL, UK

\section{Nazmul Karim}

Centre for Fine Print Research, University of West of England, Bristol, BS3 2JT, UK

\section{Forkan Sarker ( $\square$ forkan@duet.ac.bd)}

Department of Textile Engineering, Dhaka University of Engineering and Technology https://orcid.org/0000-0002-6504-6822

\section{Research}

Keywords: natural fibres, glycine, surface treatments, tensile properties

Posted Date: January 26th, 2021

DOI: https://doi.org/10.21203/rs.3.rs-151073/v1

License: (c) (i) This work is licensed under a Creative Commons Attribution 4.0 International License. Read Full License 


\section{Structural Performance of Chemically Modified Natural Jute Yarn for Strength Demanding Composite Applications}

Md. Ashadujjaman ${ }^{a}$, Abu Saifullah ${ }^{b}$, Darshill U Shah ${ }^{c}$, Minglonghai Zhang, Mahmudul Akonda ${ }^{e}$ Nazmul Karimf, Forkan Sarker ${ }^{a^{*}}$

${ }^{\text {a }}$ Department of Textile Engineering, Dhaka University of Engineering \& Technology, Gazipur-1700, Bangladesh

${ }^{\mathrm{b}}$ Advanced Materials and Manufacturing (AMM) Research Group, School of Mechanical and Design Engineering, University of Portsmouth, Portsmouth PO1 3DJ, UK

${ }^{\mathrm{c}}$ Department of Architecture, University of Cambridge, Cambridge, CB2 1PX, UK

${ }^{\mathrm{d}}$ Institute of Textile and Clothing, The Hong Kong Polytechnic University, Hong Kong

${ }^{\text {e }}$ School of Materials. The University of Manchester, Manchester, M13 9PL, UK

${ }^{\mathrm{f}}$ Centre for Fine Print Research, University of the West of England, Bristol, BS3 2JT, UK

Corresponding author: Dr. Forkan Sarker, email: forkan@duet.ac.bd 


\begin{abstract}
Manufacturing natrual based high-performance composites is becoming a greater interest to the composite manufacturers and to their end users due to their bio-degredability,low cost and availability. Yarn based textile architecture is commonly used in manufacturing these composites due to their excellent formability. However, for using natural based yarn as a reinforcing architectures in high load bearing structural composite applications, a significant improvement in mechanical performance is required. Particularly, jute fibre yarn suffers with poor mechanical properties due to the presence of fibrillar network, polysacharides and other impurities in the fibre. For achieving this, we use aqueous glycine treatment $(10 \%, \mathrm{~W} / \mathrm{V})$ on alkali $(0.5 \%, \mathrm{~W} / \mathrm{V})$ and untreated jute yarns for the first time. The glycine treatment on alkali treated jute yarns (ATG) shows a huge improvement in tensile strength and strain values by almost $\sim 105 \%$ and $\sim 50 \%$ respectively compared to untreated jute yarns (UT) because of the strong interactions and bonds developed between glycine, alkali and jute yarns. It is believed that the newly developed glycine treated jute yarns will be helpful to promote jute yarns in composite industries where load-bearing is primary requirement and replace their synthetic counterparts.
\end{abstract}

Keywords: natural fibres, glycine, surface treatments, tensile properties 


\section{Introduction}

Fibre-reinforced composites have gained significant interests in recent years, due to their design flexibility, durability, chemical resistance, and relatively higher strength and stiffness at low weight ratio. Traditionally, fibre reinforced composites are composed of synthetic fibres including glass, carbon and aramid as reinforcements in a polymer matrix (Karim et al. 2018). However, synthetic fibres are not environmentally friendly as they are manufactured from fossil fuels, associated with relatively higher energy consumption and carbon emission. Natural fibres reinforced composites can be environmentally sustainable alternative to their synthetic counterpart, due to lower environmental impacts including less carbon emission, less energy consumption and biodegradability (Karim et al. 2014, 2015; Pickering et al. 2015). The most promising natural plant fibres are jute, hemp, ramie, sisal, flax, and bamboo which could potentially replace synthetic fibers for various applications. Arguably, jute is the most attractive alternative amongst other natural plant fibres, due to its abundance, low production cost, lower density and high individual fibre length, as well as reasonable mechanical properties (Pandey et al. 2010; Sarker et al. 2018). In addition, Jute is the second most produced natural fibre in the world after cotton ( $\sim 3.63$ million tons $)$, and at least $\sim 50 \%$ cheaper than flax and other similar natural fibres. The use of jute for various applications could boost the farming economies of developing countries such as Bangladesh and India, where it is mostly produced.

The mechanical properties of jute are related to its relatively higher degree of crystallinity ( $\sim 58 \%)$, and higher cellulose content $(\sim 70 \%)$ (Table S1, Supporting Information) (Defoirdt et al. 2010). Jute fibres have a 'fringed fibril model', where inter-fibrillar matrix contains hemicellulose within ultimate cells and middle lamella contains lignin between ultimate cells (Hearle 1963). The viscoelastic and tensile behaviour of jute fibre depend on such polysaccharides (e.g. hemicellulose, lignin and pectin) and their relative proportion, because they create links between the cellulosic microfibrils and are responsible for stress transfer 
among them (Mukherjee et al. 2008). It has been reported in the previous study that the removal of polysaccharides eliminate the microvoids present between the ultimate cell and middle lamella of the fibre. As a result, microfibrils present in the fibre become more parallel and homogeneity of the fibre improves which results in improvement of the failure stress, failure strain and stiffness of jute fibres (Mukherjee et al. 2008). The alkali treatment is the most commonly used method to remove polysaccharides i.e. hemicellulose, lignin, pectin, which improves the load bearing capacity of jute fibre as a reinforcing material for fibre reinforced composites (Mukherjee et al. 2008; Sarker et al. 2018). However, jute fibre still contains microvoids among the fibrils which limit their load bearing capacity and create a weak fibre/matrix interface (Sarker et al. 2018). Previous studies have reported the removal of such defects via chemical,(Gassan and Bledzki 1999; Saha et al. 2010; Arfaoui et al. 2017) physical(Militký and Jabbar 2015) and nanomaterials modifications(Sarker et al. 2018, 2019; Dang et al. 2019) of jute fibres, which are time consuming and expensive. Additionally, there are concerns with nanomaterials safety and their potential carcinogenic nature to health. The alkali treatment is the commonly used chemical medication for natural fibres as it removes surface waxes and affects hemicelluloses. The alkali treatment $(0.5 \mathrm{wt} .-\%)$ of jute fibres with the prolonged exposure into the alkali solution is considered to be the most effective way of removing hemicelluloses without affecting lignins significantly (Roy et al. 2012; Sarker et al. 2018). Further to alkali treatment it is necessary to modify jute fibre to remove the flaws (microvoids) due to removal of lignins from the skin of fibre may also generate stress concentration. As a result, further chemical modification is necessary to solve this issues. However, the treatment should be cost effective, environmentally friendly and easy to scale up. At present nano surface modification is becoming popular in modifying natural fibres in composites applications. However, dealing with these materials are health hazardous and costly.

For fibre-reinforced composites (FRC), yarn-based multi-axial textile architectures offer better mechanical properties including impact, compression after impact damage and interfacial 
strength, than the most popular unidirectional yarn architectures (De Albuquerque et al. 2000; Khondker et al. 2005). Textile architectures are mainly induced with plain, twill, sateen, and knitted derivatives which are mainly manufactured from yarns. Therefore, there exist a growing demand for FRC composite preforms comprised of woven fabric with multi-axial yarn architectures. However the use of the jute yarn for structural FRC applications is limited due to it poor performance properties. The tensile strength for jute yarn was reported $\sim 42-45 \mathrm{MPa}$ only. Such a lower tensile strength is mainly due to the fibre impurities and the twist imparted to the fibre during spinning into yarn.(Sharif Ullah et al. 2017; Bensmail et al. 2019). In addition, the strain to failure of jute yarn was found to be limited $\sim 6.0-7.5 \%$ with a large scattering in the value in those studies (Sharif Ullah et al. 2017; Bensmail et al. 2019). Recently, few studies have been carried out on the nano-modification of natural jute yarns to increase the strength and interfacial performance of the composites (Foruzanmehr et al. 2015; Li et al. 2015). It was found that the lower value of strain \% is responsible for the amorphous phase's viscoelastic shear deformation present in the cellulose of the fibre.(Perremans et al. 2018) Such viscoelastic shear deformation can be avoided by improving the crystallinity of fibres. In addition, the tensile strength can be improved by aligning the microfibrils in the parallel directions with the loading axis (Gassan and Bledzki 1999; Perremans et al. 2018). However, the improvement of mechanical properties of natural jute yarns are still limited, and not yet well understood. Nevertheless, it is well established that the deformation of natural fibres largely depends on the interphase of elementary fibres in the yarn. Recently, glycine-based protein materials have been used in cellulosic materials to improve strain to failure and wettability of cotton fibres. Glycine was first applied on cotton fibres to improve tensile properties. It was found that the glycine treatment improved the strain $\%$ of fibres by $36 \%$ (Remadevi et al. 2018). This is mainly due to the interactions between the amino functional group of glycine and carboxylic groups present in the amorphous region of the cellulosic fibres that creates a strong chemical bond; thus, improves mechanical properties of cotton fibres. As jute has similar cellulosic structures like 
cotton, glycine is believed to have similar effects to improve the mechanical properties of Jute fibres, which has not been reported yet to the best of our knowledge. In addition, glycine is an environmentally friendly simplest form of protein-based amino-acid which has been extensively used in the drug industry. The low price and nonhazardous feature of glycine and the presence of amino-functional group has widen the scope of using this material in many applications (Bose et al. 2012).

Here, we report for the first time the improvement of tensile properties of jute yarns including the tensile strength and strain via a combination of alkali and aqueous glycine treatment. We optimize the processing conditions and parameters for such treatment to achieve the best mechanical properties of jute yarns. The untreated jute fibres were treated with a lower concentration $(0.5 \mathrm{wt} .-\%)$ of alkali treatment, followed by a subsequent glycine treatment on the alkali treated jute yarns. Surface topography of the treated and untreated jute yarns were examined using an optical and a scanning electron microscopes (SEM). In addition,, changes in the diameter of the yarns were recorded using a optical microscope, tensile properties were assessed via single yarn testing for 50 samples. We used Weibull statistics to analyse fibre failures after tensile tests. Chemical and thermal analysis were performed using Fourier transform infrared spectroscopy (FTIR), X-ray photoelectron spectroscopy(XPS) and Thermogravimetric analysis (TGA), respectively.

\section{Materials \& methods}

\section{Materials}

The jute yarns were kindly donated by UMC Jute Mills Ltd., Narsinghdi, Bangladesh. Jute (Corchorus Olitorius) plants were harvested in Bangladesh via traditional methods, and then processed in jute mills. The fibres used in the manufacturing of jute yarn were pretreated with vegetable oil to fibrillate the technical jute fibres to improve the spinnability of the fibre (Figure 1a and Figure S1a, Supporting Information). As supplied jute yarns have a linear density of 
$\sim 9.5 \mathrm{lbs} /$ spindle and a TPI of $\sim 4.09$ (Table S2, Supporting Information). Sodium hydroxide (EMSURE® ISO, >99\%) pellets were supplied by Merck (Germany). Glycine (Amino Acetic Acid, $\mathrm{NH}_{2} \mathrm{CH}_{2} \mathrm{COOH} 99.88 \%$ a white crystalline powder, Laboratory Reagent LR grade) used in this study was supplied by Fine Chemical Industries, India.

a

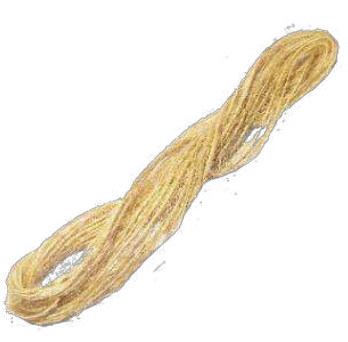

C

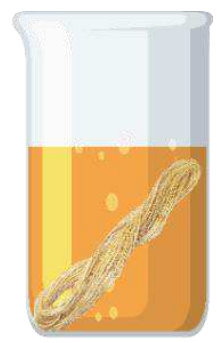

b

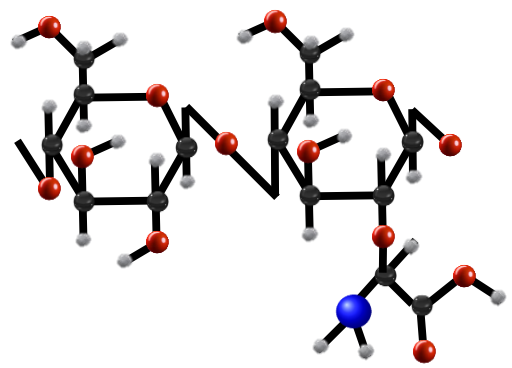

d

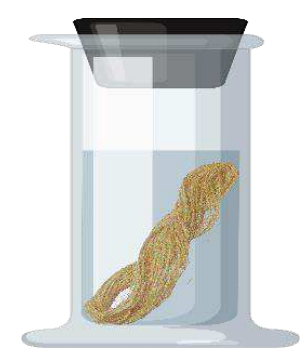

Figure 1 (a) Untreated jute yarns, (b) chemical interaction of jute fibre with glycine, (c) alkali treatment of jute yarn and (d) glycine treatment of jute fibre

\section{Alkali treatment}

The untreated jute yarn (UT) were treated with $0.25 \%, 0.5 \%, 1 \% \mathrm{NaOH}$ at room temperature for 24 hours, and $2 \% \mathrm{NaOH}$ at room temperature for 2 hours at material to liquor ratio (M: $\mathrm{L}$ ) of 1:30 (Figure 1c and Figure S1b, Supporting Information). The optimized alkali concentration was selected based on the results obtained from the tensile test of alkali-treated fibres, which was then used for glycine treatment. After alkali treatment, all samples were thoroughly washed with distilled water until all the alkali traces were removed from treated yarns. Then all the 
samples were air dried overnight at $50{ }^{\circ} \mathrm{C}$ in an oven. The optimized alkali-treated fibres were labelled as AT.

\section{Glycine treatment}

Alkali treated (AT) and untreated jute jute yarns were treated with aqueous glycine at different concentrations $(5,10,15$ and $20 \mathrm{~g} / \mathrm{L})$ at $100{ }^{\circ} \mathrm{C}$ and $\mathrm{pH} 7$ for 1.5 hour with a M:L ratio of 1:20 in an infrared lab dyeing machine ( Figure 1d and Figure S2a-b, Supporting Information). In addition, four $\mathrm{pH}$ levels $(3,5,7$ and 11) were also selected for $10 \mathrm{~g} / \mathrm{L}$ aqueous solution of glycine to see their effect on alkali treated jute yarns. All of the treated samples were thoroughly washed with distilled water and dried at $50{ }^{\circ} \mathrm{C}$ for at least 5 hours in the oven. Here, untreated jute yarn with glycine treatment is labelled as UTG, while alkali-treated jute yarn with glycine treatment was identified as ATG.

\section{Optical and scanning electron microscope (SEM)}

An optical microscope (Jiusion Original 40-1000X, China) was used to observe the fibre surface at different magnifications, and measurement of the yarn diameter (Figure S3, Supporting Information). An Scanning Electron Microscope (SEM, Model-SU 1510, Brand- Hitachi, Japan) was used to characterize the fibrillar packing of jute yarn. The samples were observed under SEM without any further coating on their surface using a low accelerating voltage $(\sim 2$ $\mathrm{kV})$.

\section{Chemical and thermal characterization}

The surface chemical composition of untreated and treated jute yarns were analyzed using a Kratos axis X-ray photoelectron spectroscopy (XPS) and a Fourier transform infrared spectroscopy (FTIR). The thermal decomposition of untreated and glycine treated jute yarn was analyzed using a TA instrument (TGA Q50, UK) from room temp to $600{ }^{\circ} \mathrm{C}$ in a nitrogen atmosphere at a $10{ }^{\circ} \mathrm{C} / \mathrm{min}$ heating rate

\section{Tensile Test}


For the tensile testing, yarn samples were taken randomly from the spool of alkali (UT, AT) and glycine-treated (UTG, ATG) jute yarns, and conditioned in a standard laboratory atmosphere $\left(55 \%\right.$ relative humidity and $20 \pm 2{ }^{\circ} \mathrm{C}$ ) for $24 \mathrm{~h}$ before the final testing. An Universal Strength Tester (Testometric Model-M250-3CT, UK), was used with a load cell capacity of 25 KG to measure the breaking force and elongation at break of jute yarn. Single yarns were tested using a $50 \mathrm{~mm}$ gauge length at a cross-head speed of $2 \mathrm{~mm} / \mathrm{min}$ as reported in the previous work. ${ }^{1}$ The yarn was set on the machine using special pneumatic yarn gripper supplied by Testometric, which ensures no slippage during testing (Figure S4 a-b, Supporting Information). Tensile modulus of the yarns was calculated from the slope of $0.1-0.3 \%$ strain of the yarn.

\section{Weibull statistical analysis}

The tensile properties of natural fibres (strength, modulus and strain \%) are often described by the weakest link theory which is based on the statement that the materials are made of small elements and the elements are linked together. A material is considered to have failed if any of these small elements has failed.(Wang et al. 2015) The cumulative probability of failure for tensile and interface properties are given by the following formula:

$$
\begin{aligned}
& P=1-\exp \left(\left(\frac{\sigma}{\sigma_{o}}\right)^{m}\right) \\
& P=1-\exp \left(\left(\frac{E}{\varepsilon_{o}}\right)^{m}\right) \\
& P=1-\exp \left(\left(\frac{\varepsilon_{s}}{\varepsilon_{o}}\right)^{m}\right)
\end{aligned}
$$

where, $\sigma$ is the tensile strength; $\sigma_{o}$ is the Weibull scale parameter and $m$ is the Weibull shape parameter. Similarly, $E$ is the tensile modulus of the fibre; $E_{\mathrm{o}}$ is the Weibull scale parameter and $m$ is the Weibull shape modulus, where $\boldsymbol{\varepsilon}_{s}$ is the tensile strain, $\boldsymbol{\varepsilon}_{o}$ is the Weibull scale parameter and $m$ is the Weibull shape parameter. Based on Equation 1-3 a double natural logarithm is taken on both sides, which is shown in Equation 4-6: 
$\ln (-\ln (1-P))=m \ln \left(\sigma-m \ln \sigma_{\mathrm{o}}\right)$

$\ln (-\ln (1-P))=m \ln \left(E-m \ln \mathrm{E}_{\mathrm{o}}\right)$

$\ln (-\ln (1-P))=m \ln \left(\boldsymbol{\varepsilon}-m \ln \boldsymbol{\varepsilon}_{o}\right)$

Where the cumulative probability of failure is related to the tensile strength $(\sigma)$, tensile modulus $(E)$, tensile strain $\left(\boldsymbol{\varepsilon}_{)}\right.$, the Weibull modulus $(m)$ and $\sigma_{0}, E_{o}$ and $\boldsymbol{\varepsilon}_{o}$ are the scale parameters of strength, tensile modulus of the fibre and tensile strain of the yarn.

\section{Results and Discussion}

\section{Surface Morphology}

Figure 2a-c show optical images of untreated and treated jute yarns (Figure S5a, Supporting Information). UT jute yarns show a loose appearance of technical fibres in the yarn, Figure $2 \mathrm{a}$. Presence of impurities such as hemicelloses and lignins in the interfibrillar network of fibres increase fibre irregularity may cause the loose appearance of fibres in the yarn.

However, after the alkali treatment, a noticeable change in the fibre packing of AT yarn (Figure 2b) was observed which could be related to the removal of hemicelluloses after alkali treatment. As a result, yarn diameters were slightly reduced from $\sim 0.92 \mathrm{~mm}$ to $\sim 0.71 \mathrm{~mm}$ (Table $\mathrm{S} 4$, Supporting Information), which is in agreement with the results obtained in previous studies.(Fernandes et al. 2013; Orue et al. 2015; Sarker et al. 2018) Glycine treatment on untreated jute fibre (UTG) slightly improved the packing of technical fibre in jute yarn while no change in the diameter was observed for UTG jute yarn (Figure S5a and Table S4, Supporting Information). 
a
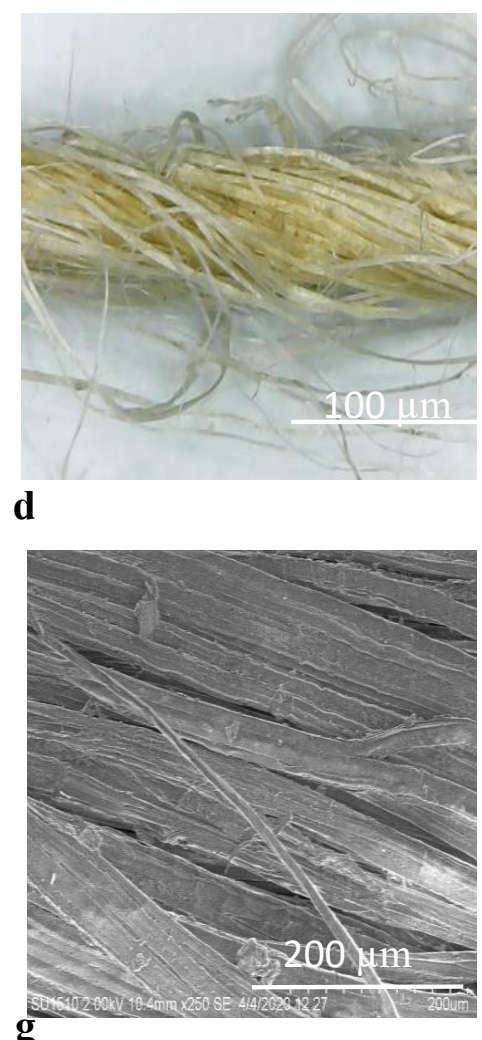

g

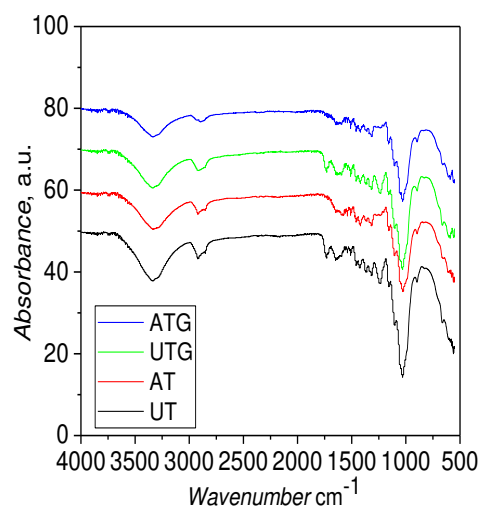

b

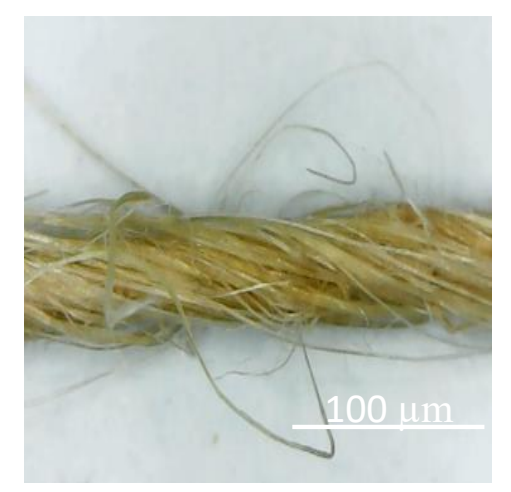

e

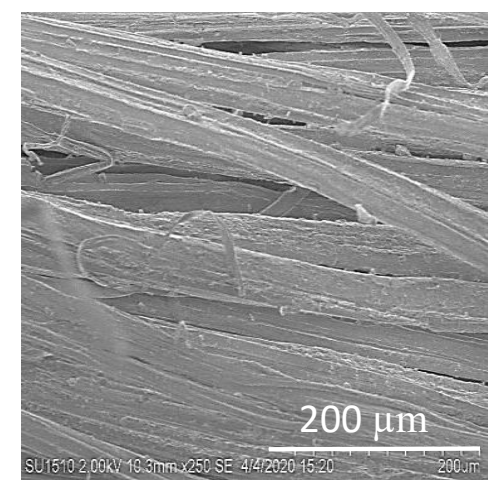

$\mathbf{h}$

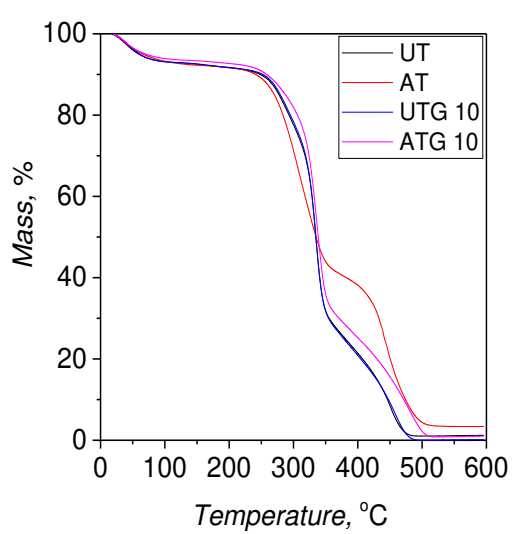

c

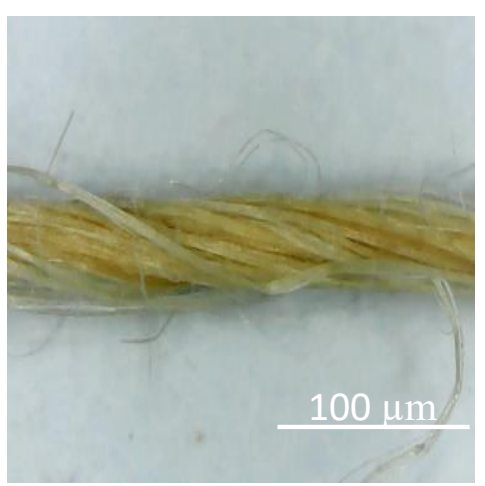

f
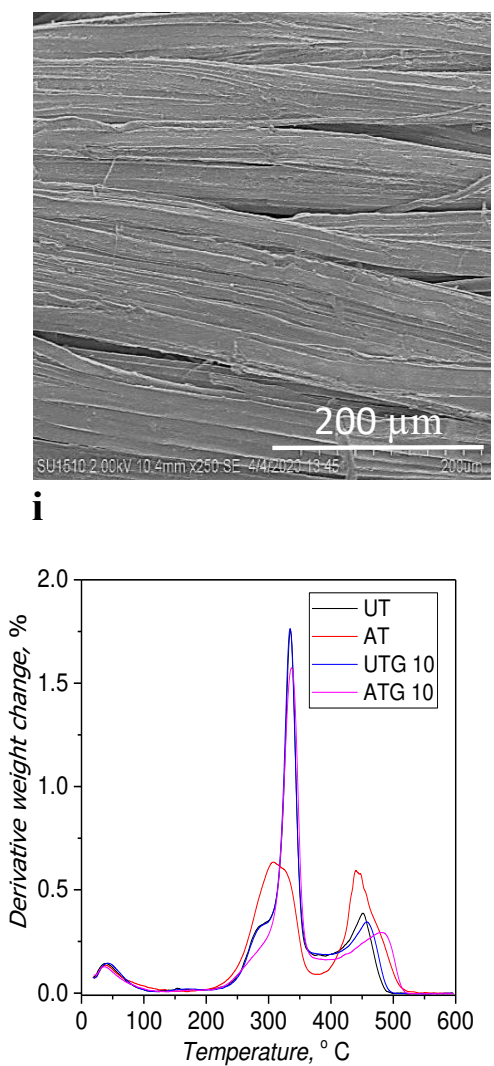

Figure 2 (a) Optical micrograph of UT jute yarn (X20), (b) Optical micrograph of AT jute yarn (X20), (c) Optical micrograph of ATG jute yarn (X20), (d) SEM micrograph of UT jute yarn (X250), (e) SEM micrograph of AT jute yarn (X250), (f) SEM micrograph of ATG jute yarn (X250), (g) FTIR spectra of untreated and treated jute yarns, (h) TGA curves of untreated and treated jute yarns and (i) Derivation weight $\% V s$ temperature profile curves of untreated and treated yarn. 
However, glycine treatment on alkali treated jute yarn (ATG) enabled a significant tight packing of the fibre in the jute yarn. As a result, a uniform reduction of yarn diameter (see Figure $2 \mathrm{c}$ and Table S4, Supporting Information) was observed throughout the length of the yarn, due to the technical fibre fibrillation via alkali treatment, and a suitable bonding $\mathrm{s}$ between the functional group of glycine and jute fibres. Scanning electron microscope (SEM) was used to investigate the fibrillar arrangement and surface smoothness of the fibre after alkali and glycine treatments. (Figure 2d-f and Figure S5b, Supporting Information). Figure 2d shows scattered, non-uniform and uncleaned technical fibre surfaces in the UT yarn. The top surface of UT yarn is covered with foreign matters such as oil, waxes, and binding materials such as lignin and hemicelluloses. Alkali treatment removed such impurities and improved the fibre surface roughness (Aziz and Ansell 2004; Stocchi et al. 2007; Sarker et al. 2018) (see Figure 2e). In addition, alkali-treated fibres show grooved appearances which clearly indicates the presence of individual fibre cells (Figure 2e) and in agreement with previous studies.(Mukherjee et al. 2008)'(Mwaikambo 2009) It could be explained by the fact that hemicelluloses that are located in the inter-microfibrillar region are sensitive to alkali solutions and can easily be removed during the alkali treatment, which causes an individual fibre fibrillation in the yarn. The application of glycine on untreated yarn (UTG) improved the connection of technical fibres, Figure 2f. However, glycine treatment on alkali treated yarns (ATG) increases not only the fibre packing but also the interconnection between the fibrillated fibres created by alkali actions (Figure 2f). Such improved interconnections create tight fibre packing, and ultimately reduce the yarn diameter similar to the ATG yarn.

\section{Chemical and Thermal Characterizations of Coated Jute Yarns}

Figure $2 \mathrm{~g}$ shows the FTIR spectra of UT, AT, UTG and ATG jute yarns, which demonstrates four characteristics peaks for UT jute yarns.(Roy et al. 2012; Sarker et al. 2018) The peak located at $\sim 3400 \mathrm{~cm}^{-1}$ is responsible for the stretching of hydrogen bond, which is originated 
from the hydroxyl groups present in the cellulose, hemicellulose and lignin of jute fibres. The peaks between 2900 and $2700 \mathrm{~cm}^{-1}$ are for the C-H stretching of alkyl groups of cellulose, lignin and hemicelluloses present in jute fibres. In addition, FTIR spectrum of untreated jute fibres show peaks at $\sim 1738$ and $\sim 1249 \mathrm{~cm}^{-1}$ band. The peak at $\sim 1738 \mathrm{~cm}^{-1}$ is for C-O stretching of carboxylic and ester groups from hemicelluloses presents in the interfibrillar region of UT jute fibres. Furthermore, the band at $1249 \mathrm{~cm}^{-1}$ is for the C-O stretching of acetyl groups from lignins of untreated jute fibres. After alkali treatment, these peaks were disappeared which is in agreement with a previous study.(Sarker et al. 2018) The disappearance of such peaks clearly confirms the removal of hemicellulose and lignin from the bundle of technical jute fibres after alkali treatment, which is evident from the optical and SEM images of AT jute yarns (Figure $2 b, e)$, and could be explained by the formation of Na-cellulose from the reaction between the cellulose and $\mathrm{NaOH}$, Figure 3 .

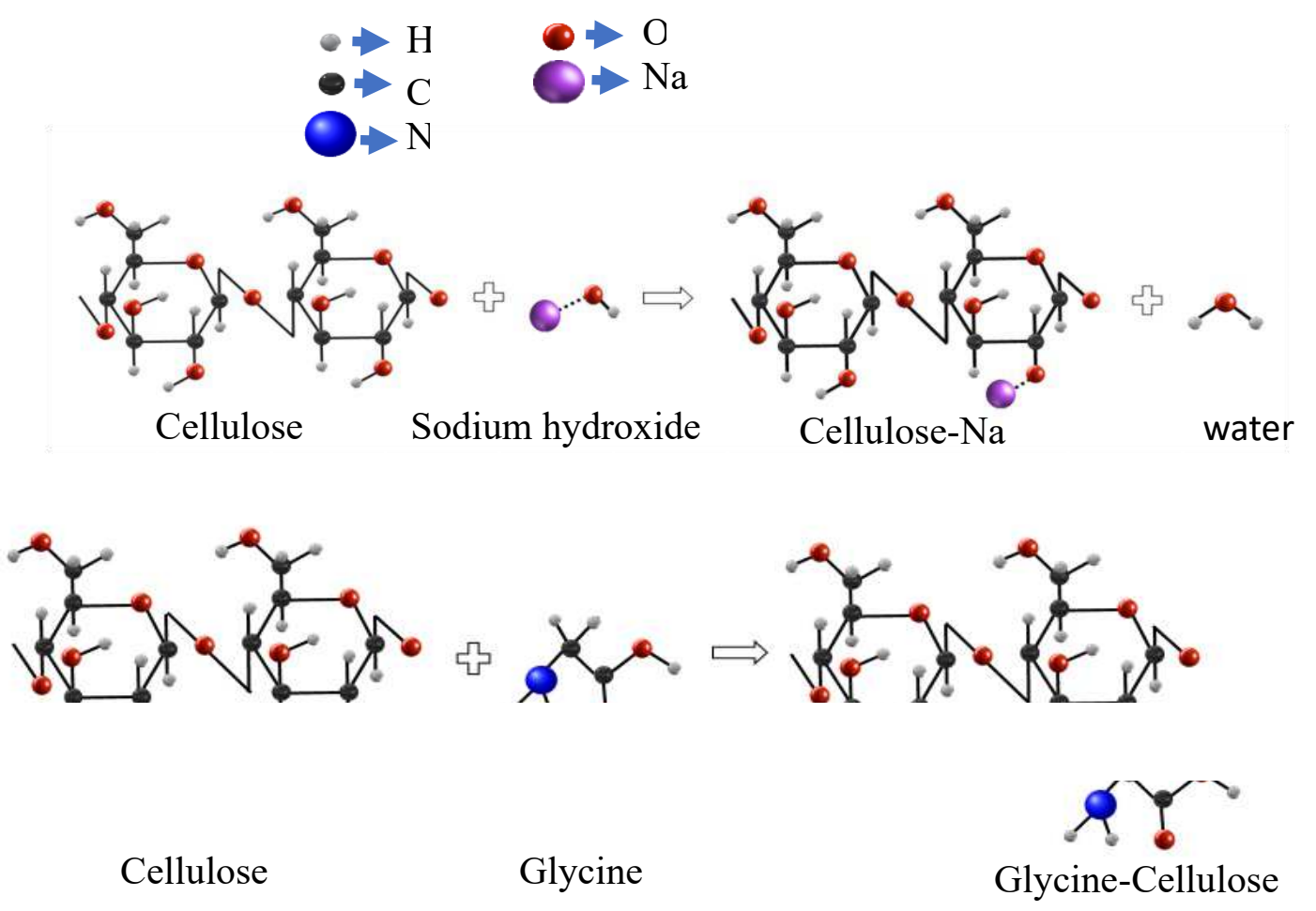

Figure 3 Possible interaction between the jute fibre with sodium hydroxide and glycine

For glycine treatment on UT jute yarn, no additional absorption peaks were observed, which may be due to the presence of impurities in jute fibre that restricts the reaction between the 
glycine compound and jute fibre. However, ATG jute yarns show slightly extended peaks at $\sim 1540 \mathrm{~cm}^{-1}$ and $\sim 570 \mathrm{~cm}^{-1}$, which is possibly due to the formation of amide bond between the amine groups of glycine and carboxylic acid groups of jute fibres. Such observation is further supported by the elimination of the carboxylic ester peak at $\sim 1732 \mathrm{~cm}^{-1}$ after glycine treatment. In addition, the peak at $570 \mathrm{~cm}^{-1}$ indicates the formation of $\mathrm{N}-\mathrm{C}=\mathrm{O}$ bending(Saroj et al. 2013) again possibly due to the interaction between amine functional groups of glycine and carboxyl groups of jute fibres, (Figure $2 \mathrm{~g}$ ) Furthermore, , the broadening of the peak at $\sim 3200 \mathrm{~cm}^{-1}$ may be due to the formation of hydrogen bond between the functional groups of glycine and alkalitreated jute fibres.

The thermal gravimetric analysis (TGA) of UT and treated jute yarns show up to 4-5\% mass loss at $\sim 100{ }^{\circ} \mathrm{C}$, which indicates the evaporation of water presents in jute fibre (up to 15\%).(Sarker et al. 2018) UT yarns showed two decomposition peaks at $\sim 298{ }^{\circ} \mathrm{C}$ and $\sim 349{ }^{\circ} \mathrm{C}$, which are related with the de-polymerization of hemicelluloses, and the decomposition of cellulose after heating, respectively.(Orue et al. 2015) However, AT jute yarns show a reduction in the onset decomposition temperature to $\sim 272^{\circ} \mathrm{C}$ and increase in the end-set decomposition to $\sim 356^{\circ} \mathrm{C}$ ( Figure $2 \mathrm{~h}$ and Table S3, Supporting Information), may be due to the removal of polysaccharides, and the increment of crystallinity for the alkali-treated AT jute yarns.(Sarker et al. 2018) In addition, the higher percentage of residues in the AT yarns indicate the improvement of thermal stability of the fibre(Kandola et al. 2016). Both ATG and UTG yarn show significant improvement in the on-set and end-set decomposition temperature of the jute yarns. For example, ATG yarns exhibit onset temperature of $\sim 306{ }^{\circ} \mathrm{C}$ and end-set decomposition temperature of $\sim 361{ }^{\circ} \mathrm{C}$ (Figure $2 \mathrm{~h}$ ). Such improvement in the decomposition temperatures is related to the improvement of crystallinity of jute fibre after the reaction taking place between the glycine and cellulose of jute fibres.

Furthermore, the derivatives of TGA curves for untreated and treated jute yarns show three peaks, where the first peak at $290{ }^{\circ} \mathrm{C}$ indicates the onset of decomposition of fibre; second peak 
at $345^{\circ} \mathrm{C}$ indicates the decomposition of hemicellulose and celluloses, and the third peak at $440{ }^{\circ} \mathrm{C}$ indicates the presence of polysaccharides in the fibre (Figure 2i). After these peaks, the stability in the curve present the percentage of ash after the decompositions.(Müssig and Haag 2015) For ATG yarns all of three peaks significantly improves is also the reflection of thermal stability improvement of the yarns.

We also performed XPS analysis to quantify the atomic content of carbon, oxygen, nitrogen on the fibre surfaces, and C/O ratio for different treatment conditions. XPS analysis shows that the untreated yarn (UT) has higher $\mathrm{C} / \mathrm{O}$ ratio of $\sim 3.93$ (Figure $4 \mathrm{a}$ ) due to the abundance of natural binding components such as waxes, lignin and hemicelluloses on the surface of untreated jute fibres. The $\mathrm{C} / \mathrm{O}$ ratio confirmed the agreement with other natural reinforcing fibres like jute and flax were also found to be 5.45 and 4.03, respectively.(Le Duigou et al. 2014; Sarker et al. 2018) After alkali treatment (AT) C/O ratio was reduced slightly to $\sim 3.44$ due to the decomposition of binding materials (waxes and hemicelluloses) o jute fibre surface. C/O ratio reduces significantly to $\sim 2.36$ after glycine treatment (ATG) on alkali treated jute fibres, may be due to the increase of oxygen and nitrogen containing functional groups on glycine-treated jute yarns, Figure 4a

High-resolution C1s XPS spectra of untreated and treated jute fibres show three main peaks: C-C bond ( 284.5 eV), C-O epoxy and alkoxy groups $(\sim 286.4 \mathrm{eV})$, and $\mathrm{C}=\mathrm{O}$ carbonyl groups $(\sim 288 \mathrm{eV})$, Figure 4b-e. The epoxy and alkoxy functional groups were increased significantly after glycine treatment on untreated fibres, which is similar to the results obtained in previous studies.(Sarker et al. 2018; Perremans et al. 2018) 

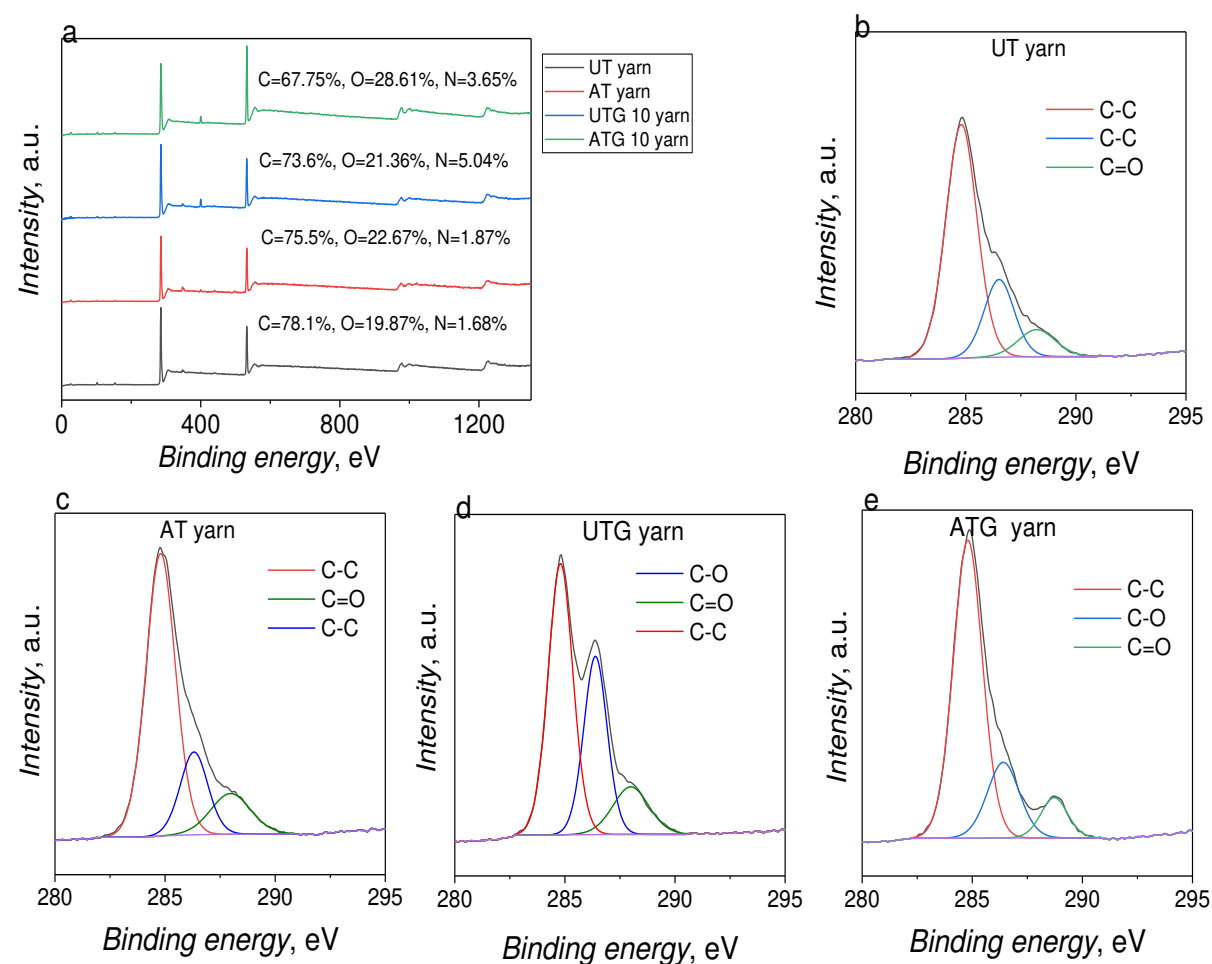

Figure 4 (a) Wide-scan XPS spectra of untreated, alkali and glycine treated jute yarns; (b) highresolution (C 1s) XPS spectra of untreated jute yarn; (c) high-resolution (C 1s) XPS spectra of alkali treated jute yarn; and (d) high-resolution (C 1s) XPS spectra of untreated and glycine applied jute yarn; (i) high-resolution (C 1s) XPS spectra of alkali and glycine treated jute yarn

\section{Tensile properties}

Jute yarns, usually brittle, show a sudden decrease in load which corresponds to the failure strain of the yarn as reported by many other researchers who worked with natural fibres (Mukherjee et al. 2008; Roy et al. 2012; Fiore et al. 2016; Sarker et al. 2018). To analyze the tensile behavior of UT and surface treated-jute yarn, single yarn tensile test was conducted. Figure 5 shows a large variation in tensile properties which could be due to the variations in the fibre fineness. Therefore, 50 single yarn tests for each type of treated and untreated jute yarns were tested in this work. The values of tensile properties (tensile strength, modulus and strain\%) were statistically analyzed using a two-parameter Weibull statistical distribution (Table S6, Supporting Information). Here, we optimize the alkali concentration, the glycine percentage 
and the effects of $\mathrm{pH}$ for surface treatments of jute yarn. These results are listed in (Table S4, Supporting Information). For alkali treatment $0.5 \%$ concentration was found to the most effective in the case of $10 \mathrm{~g} / \mathrm{L}$ glycine concentrations which is considered the best suited glycine concentration in this study (see Table S4, Supporting Information). The effects of glycine percentage on the alkali-treated jute fibre was studied and optimized as $10 \mathrm{~g} / \mathrm{L}$ (Table S4, Supporting Information). The effect of $\mathrm{pH}$ on the tensile properties of optimized glycine-treated $(10 \mathrm{gm} / \mathrm{L})$ jute yarns was studied in order to understand the intensity of interaction between the glycine moieties and cellulose functional groups at different $\mathrm{pH}$ levels. The neutral $\mathrm{pH}(7)$ of glycine solutions was found to be good enough to improve the tensile properties of ATG jute yarns (Table S4, Supporting Information). Based on the obtained results, here we used 0.5\% alkali concentration and $10 \mathrm{gm} / \mathrm{L}$ glycine solution with $\mathrm{p}^{\mathrm{H}}$ (7) for AT, UTG and ATG yarns. For tensile testing results, UT yarns show relatively lower tensile strength of $\sim 42 \mathrm{MPa}$, tensile modulus of $\sim 324 \mathrm{MPa}$ and tensile strain of $\sim 7.7 \%$, Figure $5 \mathrm{~d}-\mathrm{f}$, which is agreement with previous studies.(Sharif Ullah et al. 2017; Bensmail et al. 2019) These lower mechanical properties of UT is mainly due to the waxy cementing layer on the fibre surface composed of low molecular weight fats, lignin, pectin and hemicelluloses.(Sarker et al. 2018) After alkali treatment the value of tensile strength, tensile modulus and tensile strain increase to $\sim 70 \mathrm{MPa}$, $\sim 290 \mathrm{MPa}$ and 9.7\%, respectively for AT yarns (Figure 5d and Table S5, Supporting Information ). Though no improvement in tensile modulus observed after alkali treatment, the tensile strength and strain $\%$ increase by $\sim 70 \%$ and $\sim 26 \%$, respectively, which may be due to the improvement in the packing order of cellulose chains.(Sawpan et al. 2011) Alkali solutions are commonly used as a scouring agent in the textile processing to remove the impurities from the fibre surfaces and the hemicellulose located in the interfibrillar region of the fibre.(Roy et al. 2012; Cai et al. 2016; Sarker et al. 2018) As a result, an excessive number of fibrillations is occurred in that region, which enables the improvement in the packing order. 

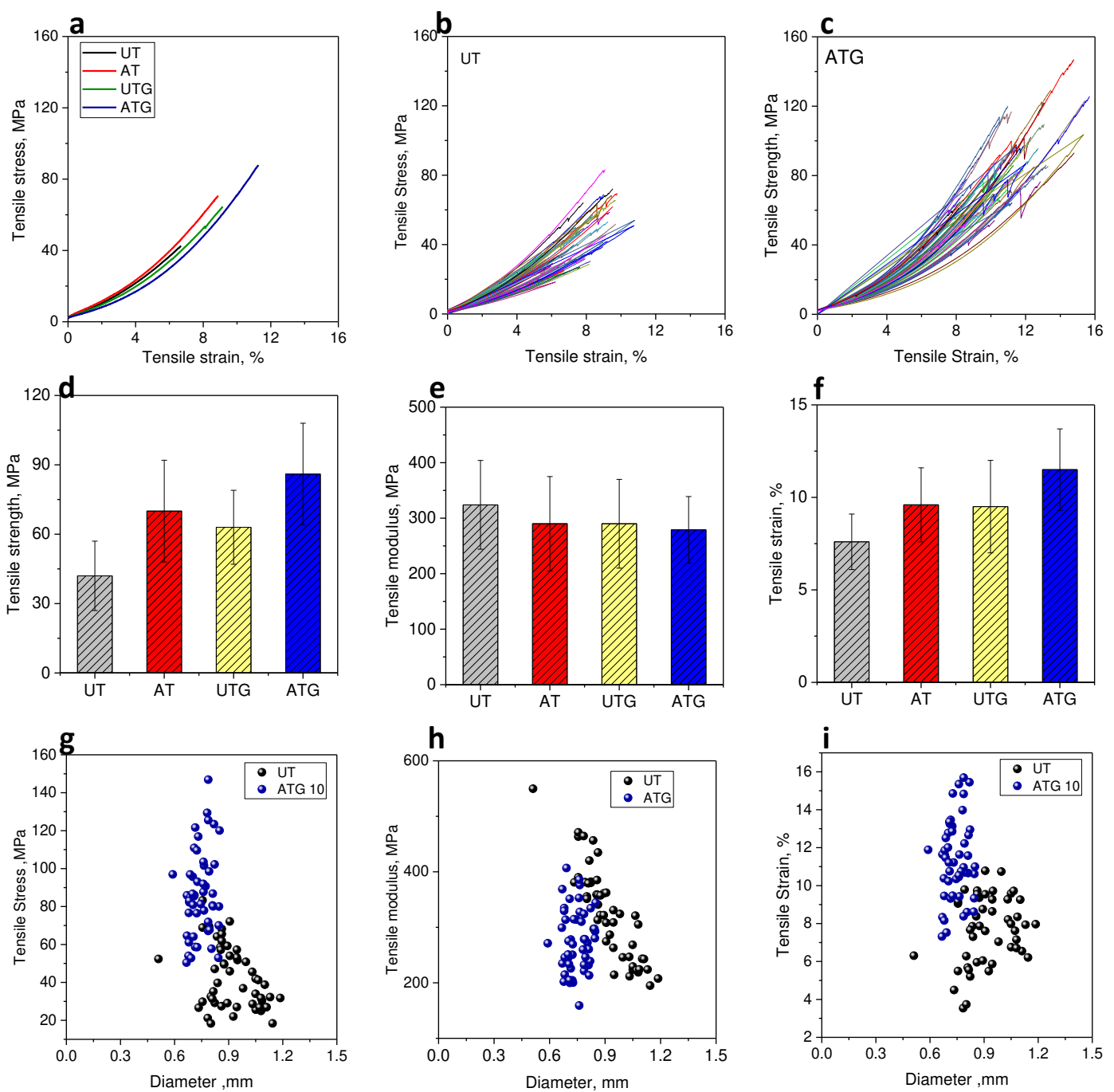

Figure 5 (a) Typical stress-strain curve of UT, AT, UTG and ATG single jute yarn, (b) stressstrain curve of untreated jute yarn, (c) stress-strain curve of alkali glycine treated jute yarn, (d) The tensile strength of untreated and treated jute yarn; (e) The tensile modulus of untreated and treated jute yarn, (f) The tensile strain\% of untreated and treated jute yarn, (g) Tensile strength versus diameter distribution of untreated and alkali glycine treated jute yarn, (h) ) Tensile modulus versus diameter distribution of untreated and alkali glycine treated jute yarn, and (i) Tensile strain versus diameter distribution of untreated and alkali glycine treated jute yarn. 
In addition, the orientation of the elementary fibre located in the jute yarn can re-arrange themselves and parallel along the length of the yarn during tensile loading (Figure 2b). The alkali-treatment on natural fibre reduces the spiral shape of cellulose microfibrils that allow the re-arrangement of the cellulose chains and improve the tensile properties of the fibre.(Sawpan et al. 2011) Similarly, the alkali treatment of abaca fibre enabled higher tensile properties than the untreated one, due to the rearrangements of cellulose microfibril along the longitudinal axis.(Cai et al. 2016) In addition, the alkali treatment can make better arrangement of cellulose chain in the fibre which is responsible for the release of internal strain that leads to improve the strength and strain\% of jute fibre.(Bledzki and Gassan 1999) Further glycine treatments on alkali-treated jute yarns improve tensile properties significantly (Table S5, Supporting Information), Figure 5d-f . The tensile strength and strain $\%$ of AT jute yarns increase from $\sim 70$ MPa and $\sim 0.7 \%$ to $\sim 86 \mathrm{MPa}$ and $11.5 \%$ for ATG yarns, respectively, which are almost $\sim 105 \%$ and $\sim 50 \%$ increment in strength and strain values respectively compared to the UT yarn. The enhancement in the tensile strength is supported by the stress-strain curves for UT and ATG yarns, Figure 5(b, c). The possible reason for the improvement in the tensile properties of ATG yarn is related to the strong connection between the AT jute fibres in the yarn with the functional group of glycine via suitable chemical or physical bonding. The proposed reaction mechanism is provided in Figure 3. In addition, the abundance of oxygen functional group and possible formation of hydrogen bonds have been by XPS and FTIR analysis (Figure $4 \mathrm{e}$ and Figure $2 \mathrm{~g}$ ). This is in agreement with a previous study,(Remadevi et al. 2018) where they treated cellulosic cotton fibre with glycine and found a significant increment in the tensile properties due to the bonding between glycine and cellulosic fibres. In addition, glycine can form zwitterion, which is a compound with no electrical charge since it has both positively and negatively charged functional groups. Interaction between the glycine moieties with the hydroxyl groups of jute fibre takes place in the amorphous region of fibre which renders in absorbing more energy 
during the mechanical loading of the fibres which ultimately improves overall tensile properties of ATG yarn.(Remadevi et al. 2017, 2018)
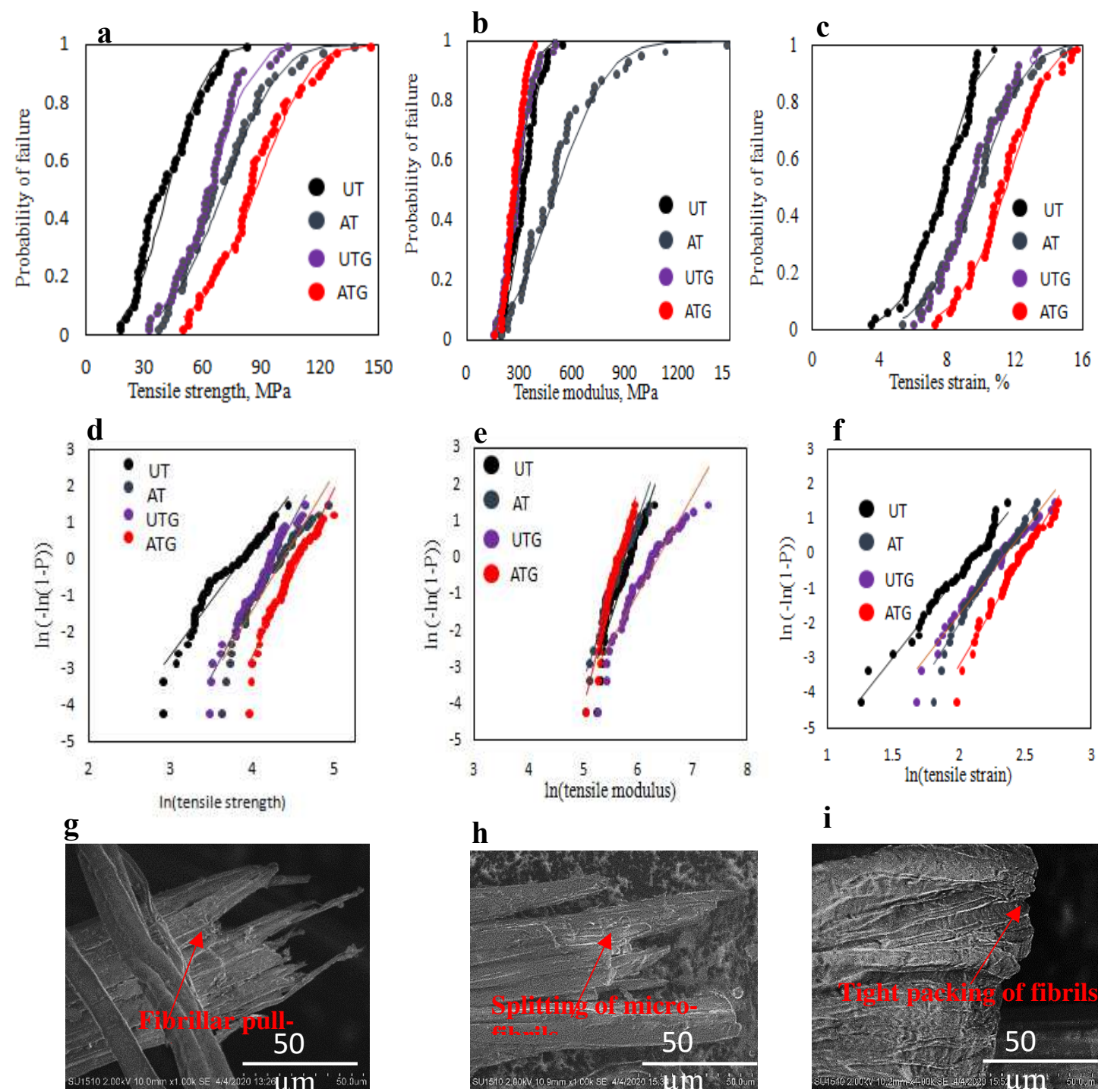

Figure 6 (a)Tensile strength data fitted to a two-parameter Weibull probability distribution as a function of surface treatment; (b) tensile modulus data fitted to a two-parameter Weibull probability distribution as a function of surface treatment; (c) tensile strain data fitted to a twoparameter Weibull probability distribution as a function of surface treatment; (d) ln curves of Weibull parameter plot distribution considering the tensile strength; (e) ln curves of Weibull parameter plot distribution considering the tensile modulus; (f) ln curves of Weibull parameter plot distribution considering the tensile strain; (g) SEM fracture of untreated jute yarn after tensile test at X250 magnification; (h) SEM fracture of alkali treated jute yarn after tensile test at X250 magnification and (i) SEM fracture of alkali glycine treated jute yarn after tensile test at X250 magnification 
The improved mechanical properties could also be described based on the SEM image observations found in Figure $2 \mathrm{f}$ of this study where an excellent fibre packing and the paralleled, fibrillated fibres interconnection were achieved for ATG yarns. As a result, there was no stress decay to print the fibre in parallel direction leading to improve the stress carrying capacity of ATG yarn during tensile loading applications. Between ATG and UTG yarns, ATG yarns showed better tensile strength and strain properties, because ATG yarns contain more hydroxyl groups for the alkali treatment which enables a better interaction with the functional groups of glycine compared to UTG yarns. However, ATG yarns exhibited lower tensile modulus value, this is possibly due to the new bonds formed in the ATG yarns which increases the the fibrillar cohesion to enhance the strain with respect to the increase of stress (see Figure 5e). Stressstrain curves of ATG yarn showed more improvement compared to UT yarns (see Figure 5c). Here, improvement in tensile properties of jute yarn is related with the better packing of fibrils in the fibre due to strong chemical interactions after glycine treatments. Beside this, we observe diameter of the yarns has changed after glycine treatment which also resulted in improving tensile properties of jute yarn is also shown in Figure $5 \mathrm{~g}$-i. This result can be supported from the SEM and optical image observations (Figure 2c\&f)) that yarn with smaller diameter have reduced porosity and less impurities in the fibre. We conduct statistical analysis to validate the data obtained after tensile experiments (see Table S6, Supporting Information). Weibull statistical distribution were performed to evaluate the scale parameter $(\alpha)$ and shape parameter $(\beta)$ of the scattered tensile results

Here $\alpha$ predicts the experimental results and $\beta$ indicates the modulus of Weibull distribution mainly known as Weibull modulus. Higher the value in Weibull modulus better the improvement in the scattering effect in the results. Figure 6a-f shows the Weibull distribution for tensile strength, modulus and strain of jute yarns as probability of failure (Figure 6a-c) and 
ln curve (Figure 6d-f). It is seen that this statistical model provided an excellent fitting of the data for tensile properties of the yarns. Moreover, Weibull distribution calculated a reasonable numerical prediction of the experimental data, provided in (Table S6, Supporting Information). It was found that tensile strength and strain values (scale parameter) of the yarn were improved after introducing the alkali and glycine treatments on jute yarn (ATG). In this case, both the probability of failure and ln curves were seen to shift from left to right significantly when ATG yarns were compared with UT jute yarns. The Weibull modulus was obtained from the ln curve of the untreated and treated yarns as shown in (Table S6, Supporting Information). UT yarn showed relatively lower value in Weibull modulus $(\sim 3,4.5$ and 4.8 , for tensile strength, tensile modulus and tensile strain respectively) due to the high scattering of UT yarns linked to the presence of impurities in the fibre located in the yarn. However, the Weibull modulus was increased to 6.1 for tensile strength, 5.9 for tensile modulus and 6.1 for failure strain of the ATG jute yarn which could be because of the better bonding between the jute fibre and the glycine, as we discussed in the earlier sections of this work. The higher value in Weibull modulus for the jute yarn were found in similar to synthetic fibres reported in the literature. Chawla et al.(Chawla et al. 2005) experimented the value of 4.6 for the Weibull modulus of ceramic fibre, whereas this study calculated the Weibull modulus of 6.1 of ATG yarns which confirmed the weakest link in the fibre caused by flaws present in the fibre was reduced significantly after introducing alkali and glycine treatment on jute yarns.

\section{Fractographic study of jute fibre yarn}

We investigated the fracture specimen of different treated jute yarns using SEM. In this investigation we observed that bundles of micro-fibrils are present in yarn which can be seen in Figure 6g-i. In the case of broken specimen from UT yarn, a very uneven fracture of jute fibre bundles with fibre pull-out from the skin of UT yarn is visible in Figure 6g. This might be due to the presence of impurities into the interfibrillar network of UT yarn which is also 
supported by other studies (Mwaikambo 2009; Sarker et al. 2018).. Fibre splitting was observed as the dominant fracture feature with a small amount of fibre pull-out for AT yarns (see Figure 6h). The dominance of fibre splitting might be related to the improvement in the crystallinity of AT jute fibres and removal of the hemicelluloses which act as the stress concentration points of jute fibres. Brittle fracture was occurred in the transverse direction of the UTG yarns at some extent for the glycine treatment whereas in (Figure S6, Supporting Information). ATG yarn showed a vivid brittle fracture surface without any fibre pull-out (see Figure 6i). For ATG yarns, fibrils in the yarn were broken in the same order along the transverse direction indicating that the improved packing of microfibrils created with the both alkali and glycine treatments evenly distributed along the length of the fibre.

\section{Comparative study with the literature}

A comparison was tried to make in (Table S7, Supporting Information) for the tensile properties particularly on tensile strength and strain observed between this study and other natural fiber based ( flax, hemp and jute) yarns studies reported in the literature. The studies of jute yarn mechanical properties are very limited in the literature. A direct comparison is difficult as the experimental conditions in those studies are different than this study. In addition, different fibers have different constituents' ratios, which have a direct impact on the mechanical properties. As found in the comparison, the alkali glycine treated jute yarns (ATG) showed an excellent and huge improvement both in tensile strength and strain properties in this study compared to any other reported tensile properties of jute yarns found in the literature.

\section{Conclusions}

In this study, aqueous glycine treatment was applied on untreated and alkali treated jute yarns, and their influences on the chemical, thermal, morphological and mechanical properties of jute yarn were evaluated. The results indicate an extremely positive effects of glycine treatment on

jute yarn towards structural properties improvement. Glycine treatment on alkali treated jute 
yarns (ATG) brought a remarkable improvement by almost $\sim 105 \%$ and $\sim 50 \%$ increment in tensile strength and strain properties respectively compared to untreated jute yarns. The significant improvements in the mechanical properties of newly developed glycine and alkali treated jute yarns (ATG) achieved in this work will be helpful to develop the use of jute yarn based woven or multi axial textile architectures as reinforcing elements in natural plant-based composites for load bearing and structural applications.

\section{Supporting Information}

Chemical Composition of Jute Fibre, Physical Properties of Jute Yarn; Jute Yarns and Chemical Treatments Used in This Study; Characterization and Testing Used in The Study; Surface Properties and Thermal Analysis of Jute Yarn; Thermal analysis of Jute Yarn; Tensile properties analysis ad Weibull Statistics; Fracture Surface and Comparative Study. (Figure S1S6, Table S1-S7).

\section{Acknowledgements}

Authors kindly acknowledge UMC jute mills for supplying jute fibre to conduct this research work.

\section{Authors' Information (optional)}

Not applicable

\section{Author Contribution}

FS conceived the idea, made plan and design of the experimental works. MA performed experimental work under the supervision of FS. AS performed chemical and thermal analysis of the study. MZ and NK performed the XPS analysis. MA and DS edited and reviewed the manuscript.

\section{Funding}

Not applicable 


\section{Availability of data and materials}

All data received after experiments are analyzed and presented in this manuscript

\section{Ethics approval and consent to participate}

This study does not any materials related with human participants or animals.

\section{Consent for publication}

Authors' have kindly provided their concern to publish this paper.

\section{Competing interests}

The authors declare that they have no competing interests.

\section{References}

Arfaoui MA, Dolez PI, Dubé M, David (2017) Development and characterization of a hydrophobic treatment for jute fibres based on zinc oxide nanoparticles and a fatty acid. Appl Surf Sci 397:19-29. https://doi.org/10.1016/j.apsusc.2016.11.085

Aziz SH, Ansell MP (2004) The effect of alkalization and fibre alignment on the mechanical and thermal properties of kenaf and hemp bast fibre composites: Part 1 - polyester resin matrix. Compos Sci Technol 64:1219-1230. https://doi.org/10.1016/j.compscitech.2003.10.001

Bensmail Y, el moumen A, Lmai F, Imad A (2019) The effects of the temperature on the mechanical properties of natural yarns. MATEC Web Conf 286:3003. https://doi.org/10.1051/matecconf/201928603003

Bledzki AK, Gassan J (1999) Composites reinforced with cellulose based fibres. Prog. Polym. Sci. 24:221-274

Bose S, Kuila T, Mishra AK, et al (2012) Dual role of glycine as a chemical functionalizer and a reducing agent in the preparation of graphene: An environmentally friendly method. J Mater Chem 22:9696-9703. https://doi.org/10.1039/c2jm00011c

Cai M, Takagi H, Nakagaito AN, et al (2016) Effect of alkali treatment on interfacial bonding in abaca fiber-reinforced composites. Compos Part A Appl Sci Manuf 90:589-597. 
https://doi.org/10.1016/j.compositesa.2016.08.025

Chawla N, Kerr M, Chawla KK (2005) Monotonic and cyclic fatigue behavior of highperformance ceramic fibers. J Am Ceram Soc 88:101-108. https://doi.org/10.1111/j.1551-2916.2004.00007.x

Dang CY, Shen XJ, Nie HJ, et al (2019) Enhanced interlaminar shear strength of ramie fiber/polypropylene composites by optimal combination of graphene oxide size and content. Compos Part B Eng 168:488-495. https://doi.org/10.1016/j.compositesb.2019.03.080

De Albuquerque AC, Joseph K, Hecker De Carvalho L, D’Almeida JRM (2000) Effect of wettability and ageing conditions on the physical and mechanical properties of uniaxially oriented jute-roving-reinforced polyester composites. Compos Sci Technol 60:833-844. https://doi.org/10.1016/S0266-3538(99)00188-8

Defoirdt N, Biswas S, Vriese L De, et al (2010) Assessment of the tensile properties of coir, bamboo and jute fibre. Compos Part A Appl Sci Manuf 41:588-595. https://doi.org/10.1016/j.compositesa.2010.01.005

Fernandes EM, Mano JF, Reis RL (2013) Hybrid cork-polymer composites containing sisal fibre: Morphology, effect of the fibre treatment on the mechanical properties and tensile failure prediction. Compos Struct 105:153-162. https://doi.org/10.1016/j.compstruct.2013.05.012

Fiore V, Scalici T, Nicoletti F, et al (2016) A new eco-friendly chemical treatment of natural fibres: Effect of sodium bicarbonate on properties of sisal fibre and its epoxy composites. Compos Part B Eng 85:150-160. https://doi.org/10.1016/j.compositesb.2015.09.028 Foruzanmehr Mr, Vuillaume PY, Robert M, Elkoun S (2015) The effect of grafting a nano$\mathrm{TiO}<$ inf $>2<$ inf $>$ thin film on physical and mechanical properties of cellulosic natural fibers. Mater Des 85:671-678. https://doi.org/10.1016/j.matdes.2015.06.105 Gassan J, Bledzki AK (1999) Possibilities for improving the mechanical properties of 
jute/epoxy composites by alkali treatment of fibres. Compos Sci Technol 59:1303-1309. https://doi.org/10.1016/S0266-3538(98)00169-9

Hearle JWS (1963) The fine structure of fibers and crystalline polymers. I. Fringed fibril structure. J Appl Polym Sci 7:1175-1192. https://doi.org/10.1002/app.1963.070070401

Kandola B, Sarker F, Luangtriratana P, Myler P (2016) Thermal protection of carbon fiberreinforced composites by ceramic particles. Coatings 6:. https://doi.org/10.3390/coatings6020022

Karim MN, Afroj S, Rigout M, et al (2015) Towards UV-curable inkjet printing of biodegradable poly (lactic acid) fabrics. J Mater Sci 50:4576-4585. https://doi.org/10.1007/s10853-015-9006-0

Karim MN, Rigout M, Yeates SG, Carr C (2014) Surface chemical analysis of the effect of curing conditions on the properties of thermally-cured pigment printed poly (lactic acid) fabrics. Dye Pigment 103:168-174. https://doi.org/10.1016/j.dyepig.2013.12.010

Karim N, Zhang M, Afroj S, et al (2018) Graphene-based surface heater for de-icing applications. RSC Adv 8:16815-16823. https://doi.org/10.1039/C8RA02567C

Khondker O a, Ishiaku US, Nakai a, Hamada H (2005) Tensile, flexural and impact properties of jute fibre-based thermosetting composites. Plast Rubber Compos 34:450 462. https://doi.org/Doi 10.1179/174328905x66199

Le Duigou A, Kervoelen A, Le Grand A, et al (2014) Interfacial properties of flax fibreepoxy resin systems: Existence of a complex interphase. Compos Sci Technol 100:152157. https://doi.org/10.1016/j.compscitech.2014.06.009

Li Y, Chen C, Xu J, et al (2015) Improved mechanical properties of carbon nanotubes-coated flax fiber reinforced composites. J Mater Sci 50:1117-1128. https://doi.org/10.1007/s10853-014-8668-3

Militký J, Jabbar A (2015) Comparative evaluation of fiber treatments on the creep behavior of jute/green epoxy composites. Compos Part B Eng 80:361-368. 
https://doi.org/10.1016/j.compositesb.2015.06.014

Mukherjee A, Ganguly PK, Sur D (2008) Structural Mechanics of Jute: The Effects of Hemicellulose or Lignin Removal. J Text Inst 84:348-353.

https://doi.org/10.1080/00405009308658967

Müssig J, Haag K (2015) Biofiber Reinforcements in Composite Materials. Elsevier

Mwaikambo LY (2009) Tensile properties of alkalised jute fibres. BioResources 4:566-588. https://doi.org/10.15376/biores.4.2.566-588

Orue A, Jauregi A, Peña-Rodriguez C, et al (2015) The effect of surface modifications on sisal fiber properties and sisal/poly (lactic acid) interface adhesion. Compos Part B Eng 73:132-138. https://doi.org/10.1016/j.compositesb.2014.12.022

Pandey JK, Ahn SH, Lee CS, et al (2010) Recent advances in the application of natural fiber based composites. Macromol. Mater. Eng. 295:975-989

Perremans D, Hendrickx K, Verpoest I, Van Vuure AW (2018) Effect of chemical treatments on the mechanical properties of technical flax fibres with emphasis on stiffness improvement. Compos Sci Technol 160:216-223. https://doi.org/10.1016/j.compscitech.2018.03.030

Pickering KL, Aruan Efendy MG, Le TM (2015) A review of recent developments in natural fibre composites and their mechanical performance. Compos Part A Appl Sci Manuf. https://doi.org/10.1016/j.compositesa.2015.08.038

Remadevi R, Gordon S, Wang X, Rajkhowa R (2018) Tensile, physical, and microstructure properties of glycine treated cotton fibers. Text Res J. https://doi.org/10.1177/0040517517700196

Remadevi R, Gordon S, Wang X, Rajkhowa R (2017) Investigation of the swelling of cotton fibers using aqueous glycine solutions. Text Res J. https://doi.org/10.1177/0040517516665267

Roy A, Chakraborty S, Kundu SP, et al (2012) Improvement in mechanical properties of jute 
fibres through mild alkali treatment as demonstrated by utilisation of the Weibull distribution model. Bioresour Technol 107:222-228.

https://doi.org/10.1016/j.biortech.2011.11.073

Saha P, Manna S, Chowdhury SR, et al (2010) Enhancement of tensile strength of lignocellulosic jute fibers by alkali-steam treatment. Bioresour Technol 101:3182-3187. https://doi.org/10.1016/j.biortech.2009.12.010

Sarker F, Karim N, Afroj S, et al (2018) High-Performance Graphene-Based Natural Fiber Composites. ACS Appl Mater Interfaces 10:34502-34512. https://doi.org/10.1021/acsami.8b13018

Sarker F, Potluri P, Afroj S, et al (2019) Ultrahigh Performance of Nanoengineered Graphene-Based Natural Jute Fiber Composites. ACS Appl Mater Interfaces 11:2116621176. https://doi.org/10.1021/acsami.9b04696

Saroj AL, Singh RK, Chandra S (2013) Studies on polymer electrolyte poly(vinyl) pyrrolidone (PVP) complexed with ionic liquid: Effect of complexation on thermal stability, conductivity and relaxation behaviour. Mater Sci Eng B Solid-State Mater Adv Technol 178:231-238. https://doi.org/10.1016/j.mseb.2012.11.007

Sawpan MA, Pickering KL, Fernyhough A (2011) Effect of various chemical treatments on the fibre structure and tensile properties of industrial hemp fibres. Compos Part A Appl Sci Manuf 42:888-895. https://doi.org/10.1016/j.compositesa.2011.03.008

Sharif Ullah AMM, Shahinur S, Haniu H (2017) On the mechanical properties and uncertainties of jute yarns. Materials (Basel) 10:. https://doi.org/10.3390/ma10050450

Stocchi A, Lauke B, Vázquez A, Bernal C (2007) A novel fiber treatment applied to woven jute fabric/vinylester laminates. Compos Part A Appl Sci Manuf 38:1337-1343. https://doi.org/10.1016/j.compositesa.2006.10.010

Wang F, Shao J, Keer LM, et al (2015) The effect of elementary fibre variability on bamboo fibre strength. Mater Des 75:136-142. https://doi.org/10.1016/j.matdes.2015.03.019 
Figures

a

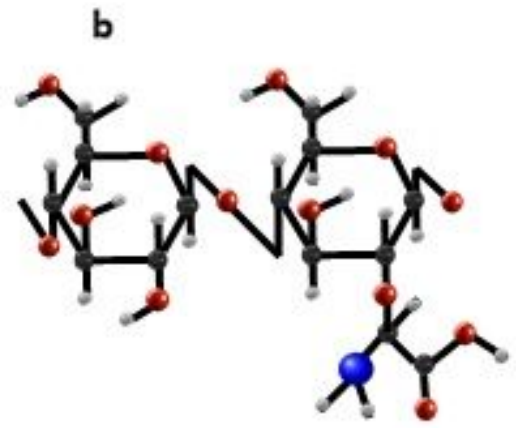

c

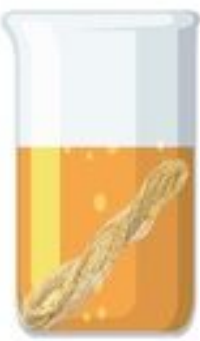

d

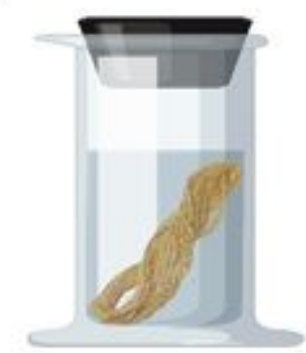

Figure 1

(a) Untreated jute yarns, (b) chemical interaction of jute fibre with glycine, (c) alkali treatment of jute yarn and (d) glycine treatment of jute fibre 
a

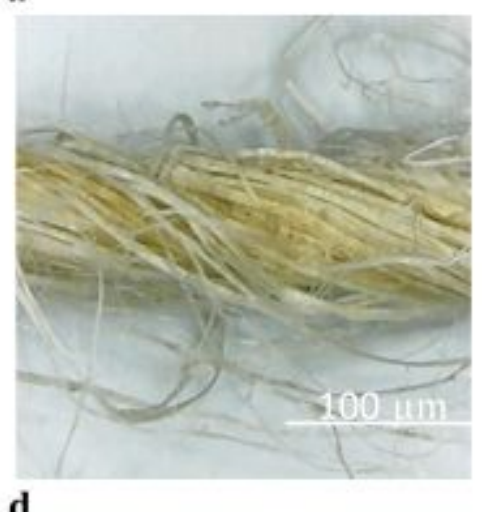

d
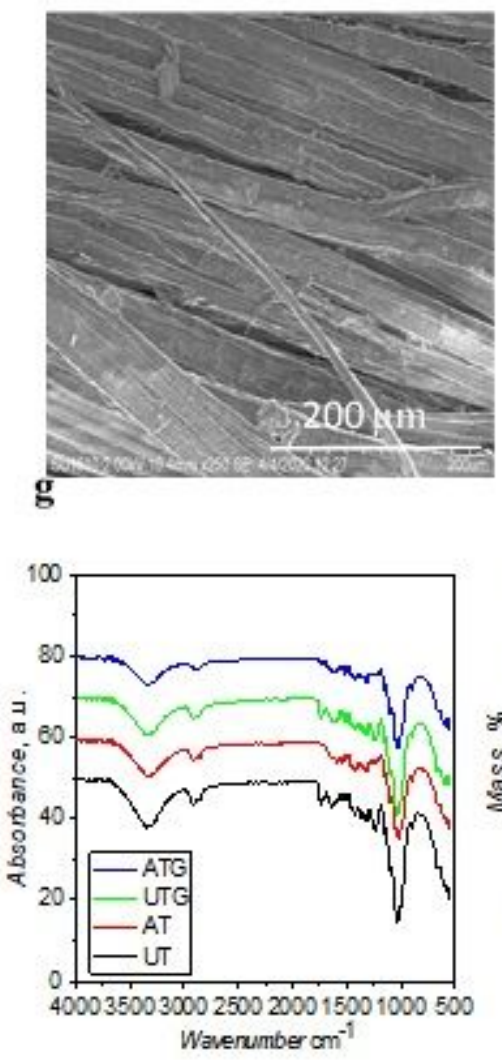

b

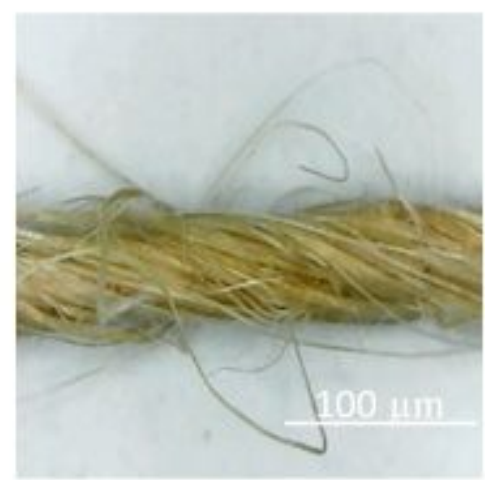

e

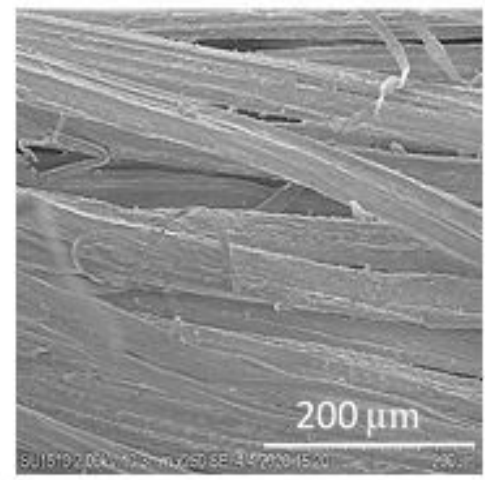

h

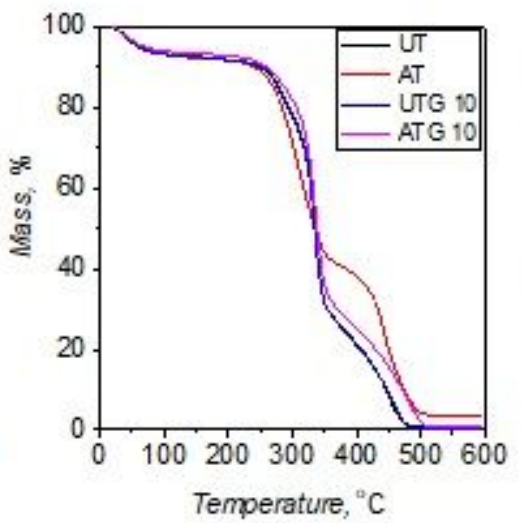

c

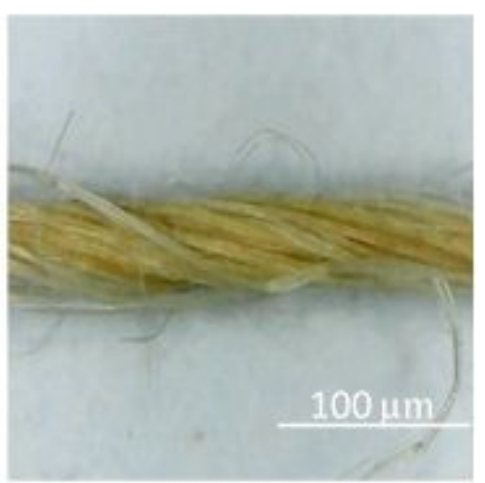

f

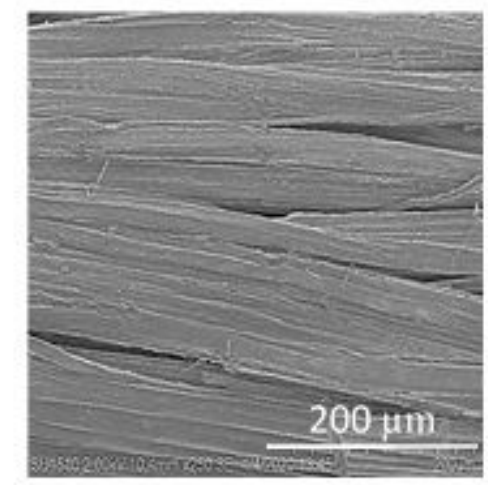

i

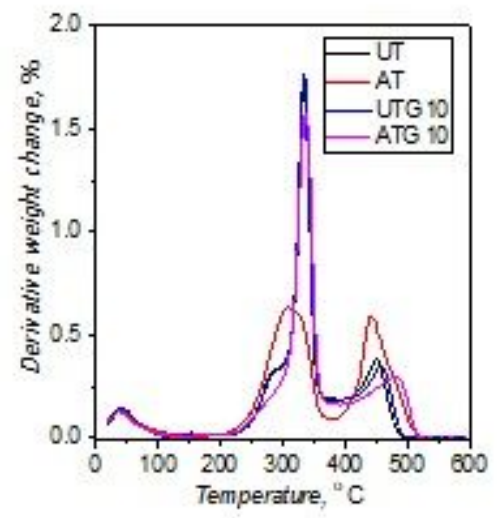

\section{Figure 2}

(a) Optical micrograph of UT jute yarn (X20), (b) Optical micrograph of AT jute yarn (X20), (c) Optical micrograph of ATG jute yarn (X20), (d) SEM micrograph of UT jute yarn (X250), (e) SEM micrograph of AT jute yarn (X250), (f) SEM micrograph of ATG jute yarn (X250), (g) FTIR spectra of untreated and treated jute yarns, (h) TGA curves of untreated and treated jute yarns and (i) Derivation weight \% Vs temperature profile curves of untreated and treated yarn. 


$$
\text { and }
$$

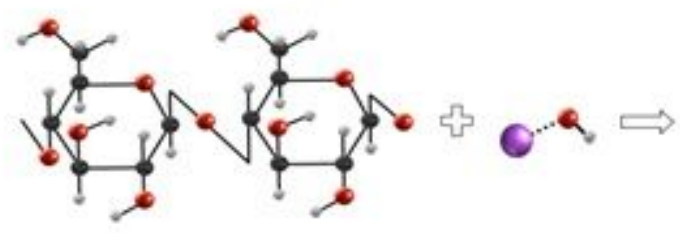

Cellulose

Sodium hydroxide
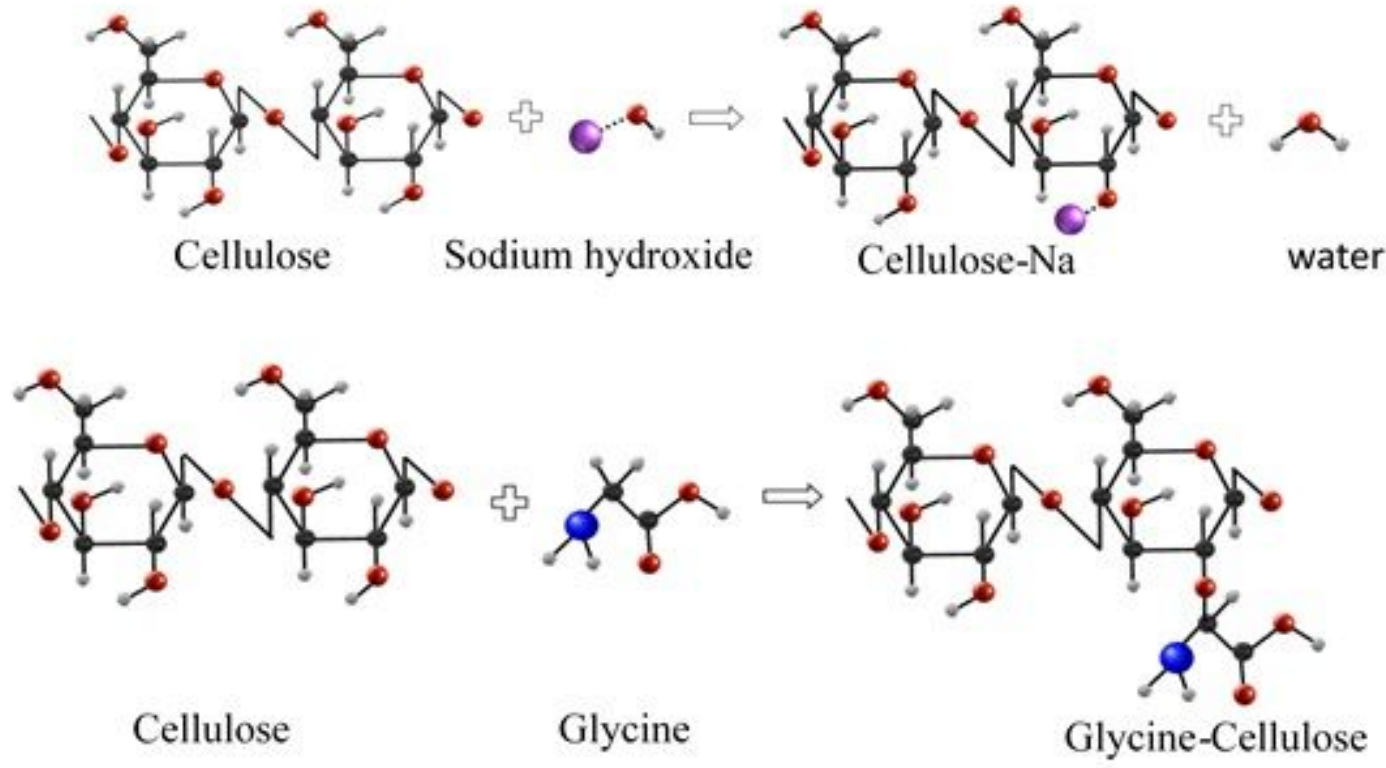

Figure 3

Possible interaction between the jute fibre with sodium hydroxide and glycine
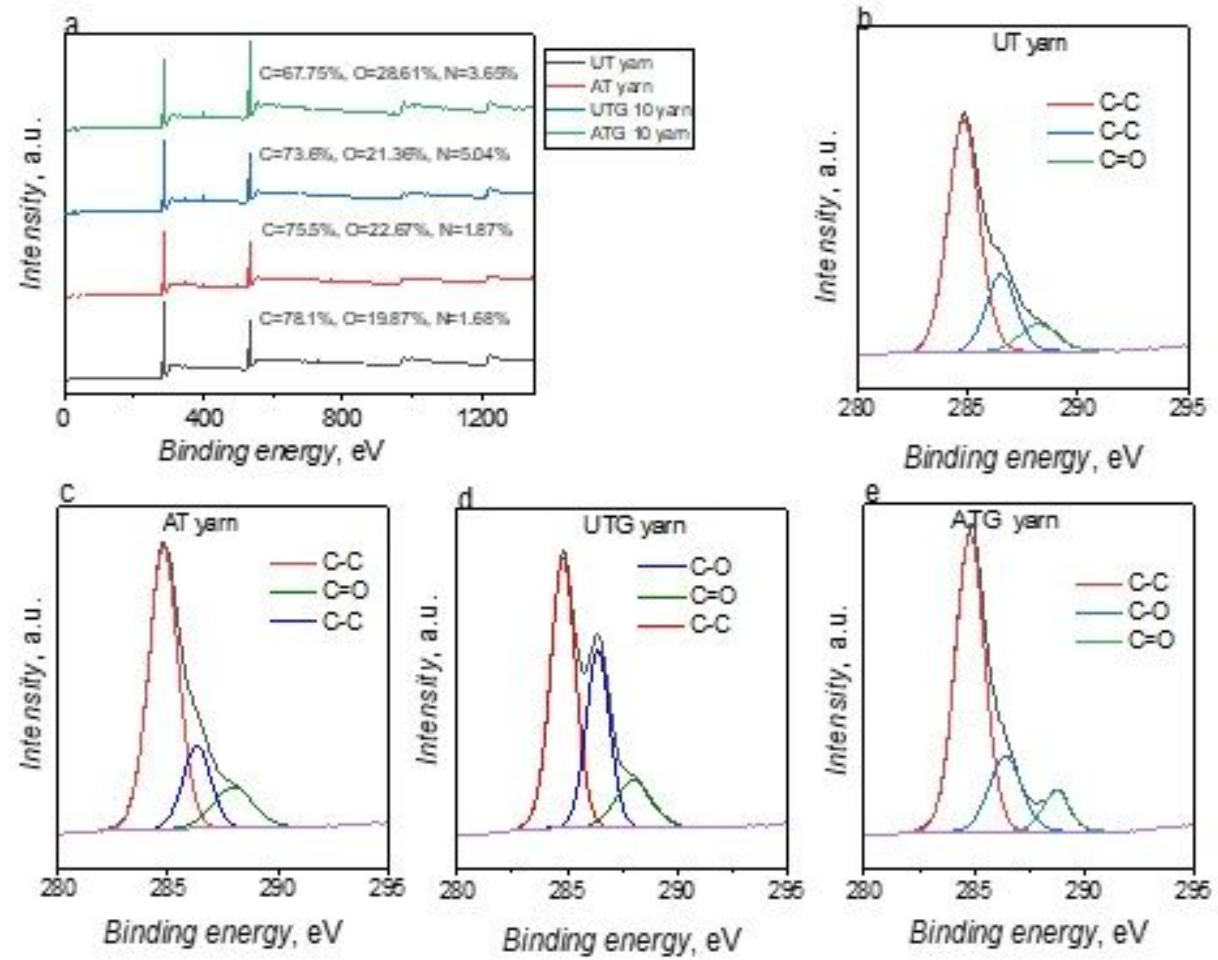

Figure 4 
(a) Wide-scan XPS spectra of untreated, alkali and glycine treated jute yarns; (b) high-resolution (C 1s) XPS spectra of untreated jute yarn; (c) high-resolution (C 1s) XPS spectra of alkali treated jute yarn; and (d) high-resolution (C 1s) XPS spectra of untreated and glycine applied jute yarn; (i) high-resolution (C 1s) XPS spectra of alkali and glycine treated jute yarn
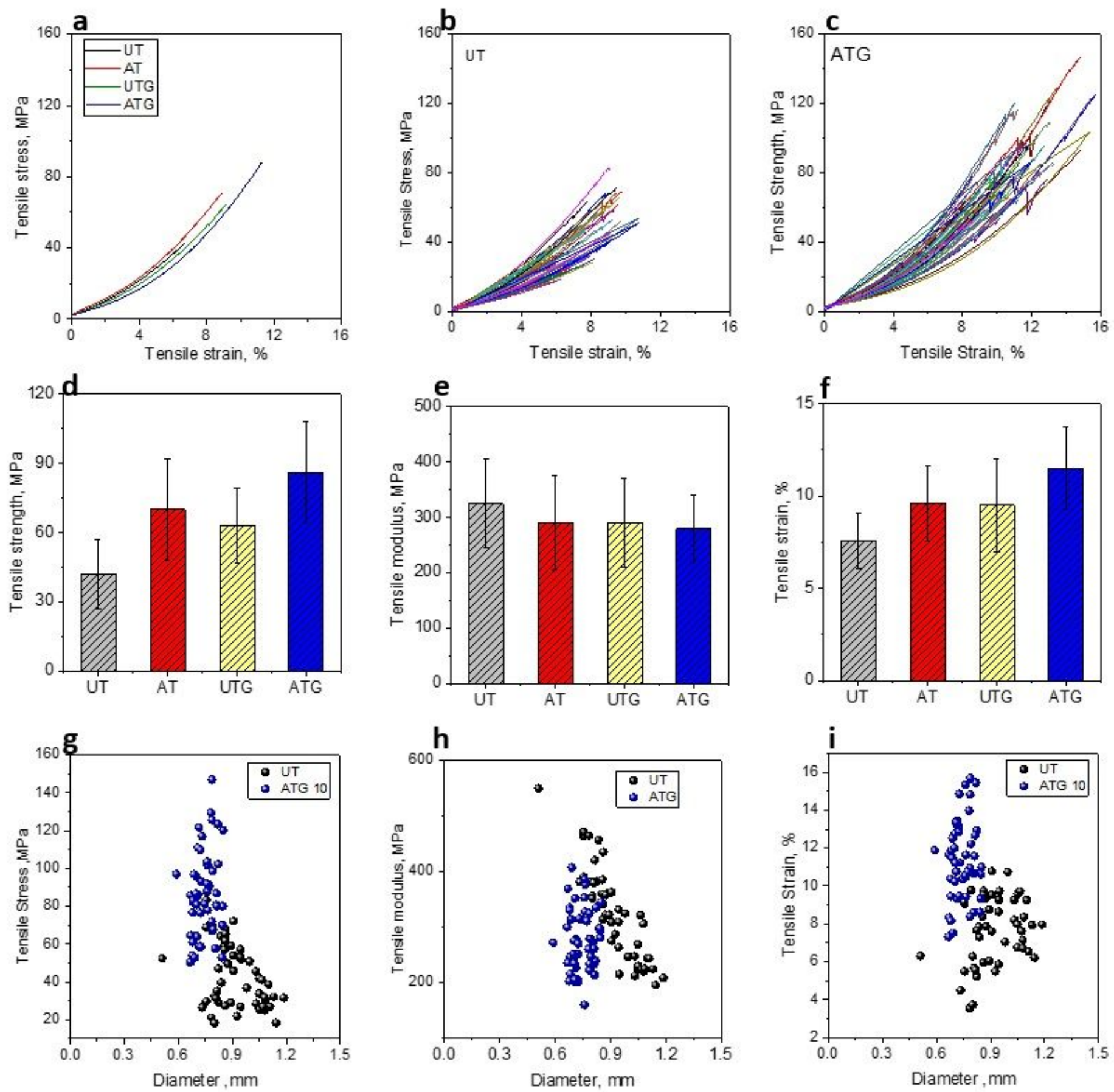

\section{Figure 5}

(a) Typical stress-strain curve of UT, AT, UTG and ATG single jute yarn, (b) stress-strain curve of untreated jute yarn, (c) stress-strain curve of alkali glycine treated jute yarn, (d) The tensile strength of untreated and treated jute yarn; (e) The tensile modulus of untreated and treated jute yarn, (f) The tensile strain $\%$ of 
untreated and treated jute yarn, (g) Tensile strength versus diameter distribution of untreated and alkali glycine treated jute yarn, (h) ) Tensile modulus versus diameter distribution of untreated and alkali glycine treated jute yarn, and (i) Tensile strain versus diameter distribution of untreated and alkali glycine treated jute yarn.
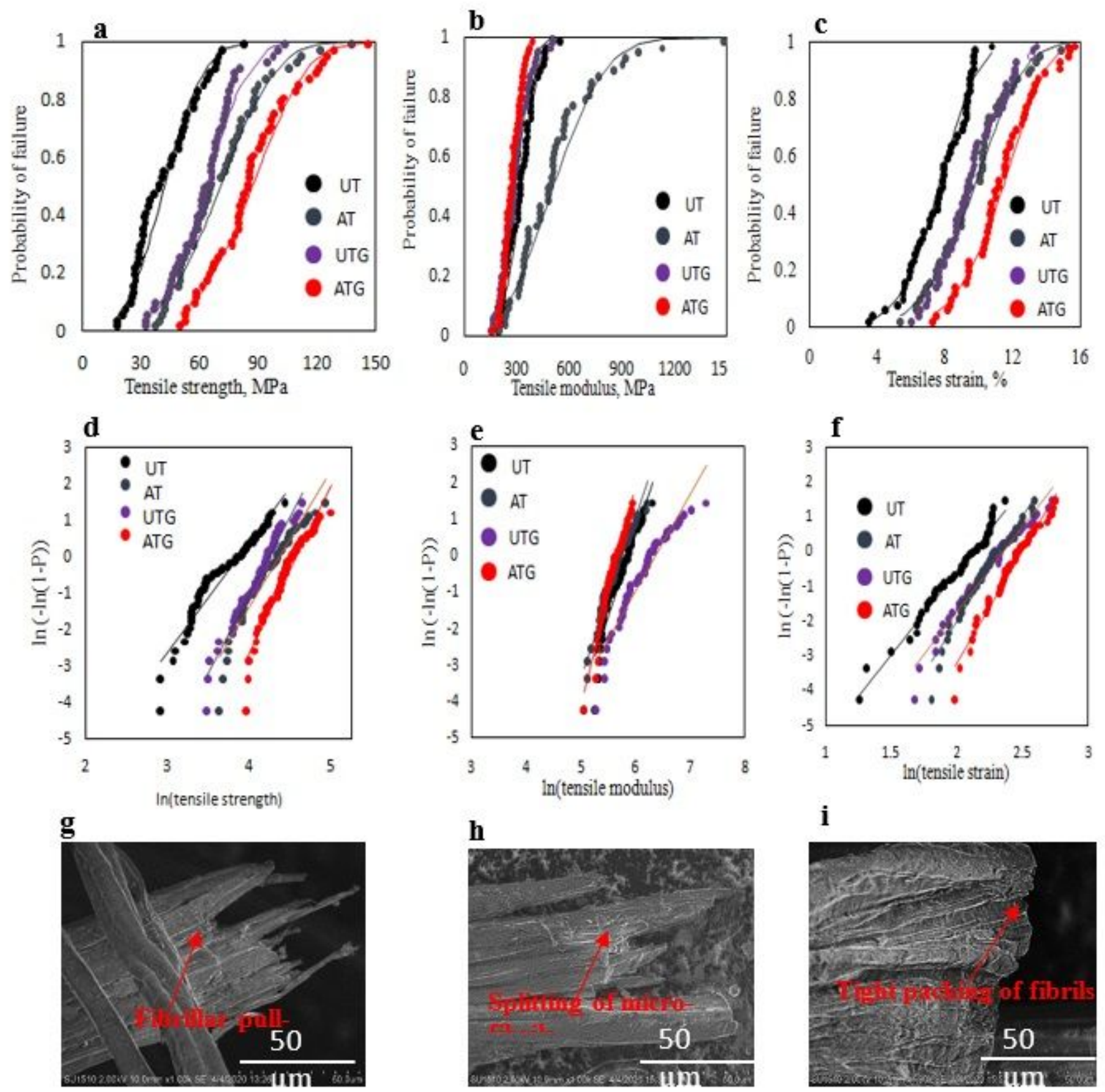

Figure 6

(a)Tensile strength data fitted to a two-parameter Weibull probability distribution as a function of surface treatment; (b) tensile modulus data fitted to a two-parameter Weibull probability distribution as a function of surface treatment; (c) tensile strain data fitted to a two-parameter Weibull probability distribution as a function of surface treatment; (d) In curves of Weibull parameter plot distribution considering the tensile strength; (e) In curves of Weibull parameter plot distribution considering the tensile modulus; (f) In curves 
of Weibull parameter plot distribution considering the tensile strain; (g) SEM fracture of untreated jute yarn after tensile test at X250 magnification; (h) SEM fracture of alkali treated jute yarn after tensile test at X250 magnification and (i) SEM fracture of alkali glycine treated jute yarn after tensile test at X250 magnification

\section{Supplementary Files}

This is a list of supplementary files associated with this preprint. Click to download.

- GraphicsFS.tif

- SupportingInformationDrForkanSarkerJMS.docx 